\title{
A physiological study of Macleod's syndrome
}

\author{
JEAN R. NAIRN AND F. J P PIME \\ From the Department of Medicine, Institute of Diseases of the Chest, Brompton Hospital, London
}

\begin{abstract}
Seven patients with Macleod's syndrome of abnormal transradiancy of one lung have been investigated with special reference to regional lung function. The principal abnormality was found to be obstruction of the airways. This was severe in the affected lung but was often present in the other lung as well. Five of the seven patients suffered from chronic bronchitis, as judged by the M.R.C. questionnaire. Although functional impairment of the affected lung was severe, it was by no means uniformly distributed there. There was evidence of defective gas transfer in all the patients who complained of breathlessness on exertion; the blood gases were only slightly abnormal at rest, and hypercapnia, in particular, was not a feature. During exercise arterial oxygen tensions tended to fall. Clinically it was found that the stethoscope gave a rough guide to the extent of regional underventilation and that radiographs were useful for judging the distribution of blood within the lung. We conclude that treatment should be conservative, directed towards avoidance of environments and habits likely to cause or exaggerate airways obstruction or bronchitis.
\end{abstract}

In 1954 Macleod described a syndrome of clinical signs and radiological appearances in the following words: 'The main features are quietening of the breath sounds and lessening of the radiographic lung markings with persistently greater transradiancy over one lung, the condition being distinguishable from simple unilateral obstructive emphysema by the small or normal size of the affected side and the absence of evidence of bronchial obstruction'. His study was based on nine cases. He went on to describe how movements of the diaphragm on the affected side are diminished, with shifting of the mediastinum towards the opposite side during expiration. In five of his patients he noted the presence of wheezing on both sides during expiration.

Since 1954 this syndrome has been noticed more frequently and has received attention from other workers. Reid and Simon (1962) studied the radiological aspects of 12 patients with the morbid anatomical and histological findings in three who had been treated by pneumonectomy. They demonstrated bronchographically that there was no obstruction to the larger bronchial branches, but that the finer bronchi and bronchioles filled poorly with the contrast medium and were irregular and distorted in outline, indicating peripheral obstruction. Examination of three lungs removed by operation showed that they were emphysematous and confirmed that the bronchioles were distorted and even obliterated by fibrosis. These lesions were patchily distributed throughout the lung. The main pulmonary arteries were virtually normal, but the peripheral branches (at acinar level) were diminished in number. The authors put forward the hypothesis that these findings were the late result of a severe bronchiolitis in infancy or early childhood, occurring before the development of the gas exchanging part of the lung was complete, and that subsequent development was arrested on account of failure to ventilate the lung properly. Other authors dispute these views on the aetiology (Belcher, Capel, Pattinson, and Smart, 1959).

Clinical reports emphasize the frequency of productive cough in subjects with this abnormality who come under medical observation. They are said to be unusually prone to repeated chest $\sigma$ infections (Dornhorst, Heaf, and Semple, 1957 ; Darke, Chrispin, and Snowden, 1960 ; Fouché, స్ Spears, and Ogilvie, 1960). The physiological 으 investigations of these and other authors (Benti-

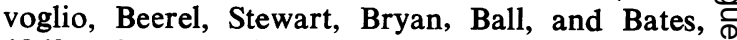
1963a; Bates and Christie, 1964) show that the $\stackrel{?}{+}$ transradiant lung takes little part in gas exchange 0 and emphasize the danger to the patients of damage from any cause to the better lung. It is clear that the prognosis in these patients depends on the condition of this lung. Some attention has been given to this by Dornhorst et al. (1957) and 
Darke et al. (1960), who have used bronchospirometry to obtain important information. The first group found that in two patients under anaesthesia unusually high pressures were required to inflate the affected lung, which emptied very slowly, indicating a high degree of airway obstruction; the other lung in these patients behaved normally. Darke et al. (1960) measured the gas exchange in the two lungs and found that the affected lung was responsible for only $21 \%$ of the total oxygen uptake and that intrapulmonary gas mixing was greatly impaired; they confirmed Dornhorst's finding of airways obstruction in the affected lung. They also mention that gas mixing in the better lung was abnormal. Bentivoglio et al. (1963a), in discussing three cases, state that 'Truly unilateral involvement of this kind results in slight total functional impairment and little if any disability'. Our experience leads us to believe that 'truly unilateral' involvement is rather rare; the distribution of the typical lesion may even be confined to only a part of one lung (as in our case 7). Whether cases such as this should be called Macleod's syndrome at all is debatable in view of the description quoted above, but the essential radiological and pathological changes are the same; Scadding (1965) has suggested 'hypertransradiancy attributable to bronchiolitis obliterans of childhood' as an appropriate description of these changes, no matter what their distribution.

In the present report we describe seven further patients studied in some detail with our attention specially directed to the function of the unaffected lung. In six of the patients a whole lung was transradiant; four of these were on the right side and two on the left. In the seventh patient the transradiancy was on the left but was confined to the left lower lobe.

\section{METHODS}

The symptoms presented by the patients were recorded by one observer using a questionnaire based on that devised by the M.R.C. Committee on Chronic Bronchitis (1960) and its appendix (Fletcher, HughJones, McNicol, and Pride, 1963). The severity of the symptoms was graded according to the answers in the way recommended by the Committee.

Clinical and radiological studies were carried out, special attention being directed to the physical sign of unilateral diminution of breath sounds.

The lung function was assessed as a whole using standard methods for measuring forced vital capacity and forced expiratory volume at one second (F.V.C. and F.E.V.1.0) ; airway conductance (the reciprocal of airway resistance) and lung volume measured in body plethysmograph (Comroe, Botelho, and DuBois, 1959 ; Briscoe and DuBois, 1958); gas transfer factors at rest and during exercise $\left(T_{\mathrm{Lco}}\right)$ using a steadystate procedure with end-tidal sampling (Bates, Boucot, and Dormer, 1955); total lung capacity (T.L.C.) and its subdivisions (functional residual capacity (F.R.C.) and residual volume (R.V.)), using the closed-circuit helium dilution technique (McMichael, 1939); and measurement of arterial blood gases at rest and immediately after exercise. For this we used a series of electrodes for measuring oxygen and $\mathrm{CO}_{2}$ tensions and $p \mathrm{H}$; the haemoglobin saturation with oxygen was interpolated from standard haemoglobin dissociation curves (Dill, 1944). The electrodes were calibrated before and after the measurement of each sample.

In addition, measurements of regional lung function were carried out using radioactive xenon $\left({ }^{33} \mathrm{Xe}\right)$ as a tracer. Briefly, the procedure is as follows (Mannell, Prime, and Smith, 1966). Six counters are placed anteriorly and six posteriorly on the chest wall of the seated immobile patient, covering upper, middle, and lower zones on each side of the chest. Anterior and posterior counts registered in each zone are summated throughout. ${ }^{133} \mathrm{Xe}$ dissolved in sterile saline is injected intravenously through a fine nylon catheter placed in the superior vena cava, and the patient holds his breath in maximal inspiration. The surface counts in each lead record the distribution of perfusion in each zone as a plateau $(R p)$ during the breath-holding period. A maximal inspiration of ${ }^{133} \mathrm{Xe}$ in air from a spirometer likewise records a rise in counts in each zone as a plateau $\left(R_{I}\right)$ during a further breath-holding period. Then the patient rebreathes in a closed-circuit spirometer system containing air and xenon and maintained at a constant volume by the addition of oxygen. A mixing, "washin' curve is recorded in each zone. When the patient has equilibrated in each zone, or at the end of six minutes, a maximal inspiration is held for a further short period, when another plateau $\left(\mathbf{R}_{E}\right)$ is recorded. An interval of at least five minutes is allowed between each manœuvre, during which the patient breathes room air.

Calculations The share of ventilation to each zone on a single maximal inspiration is called the static ventilation or $\mathrm{V}$-index. It is calculated thus:

$$
\frac{\mathbf{R}_{\mathbf{I}}}{\varepsilon \mathrm{R}_{\mathrm{I}}} \div \frac{\mathbf{R}_{\mathrm{E}}}{\varepsilon \mathbf{R}_{\mathrm{E}}}
$$

The first of these ratios indicates the share of the initial breath which reaches each region and the second indicates the proportion of the total volume surveyed into which each share goes. In other words, the V-index tells us the share of the initial breath which enters unit volume of ventilated lung in each region. It should be noted particularly that the index tells us nothing about the absolute ventilation of any part of the lung but only about the relation between one part and another. 
The 'perfusion index' (or Q-index) is calculated in a similar way after the injection of a solution of ${ }^{133} \mathrm{Xe}$ in saline. Here the regional counting rates $\left(\mathbf{R}_{\mathbf{p}}\right)$ are compared with the same equilibrium counting rates as were used for the V-index as follows:

$$
\text { Q-index }=\frac{\mathbf{R}_{\mathbf{p}}}{\varepsilon \cdot \mathbf{R}_{\mathbf{p}}} \div \frac{\mathbf{R}_{\mathbf{E}}}{\boldsymbol{\varepsilon} \cdot \mathbf{R}_{\mathbf{E}}}
$$

This indicates the share of the total blood-flow which each unit volume of ventilated lung surveyed receives.

A third and, we believe, important piece of information is derived from the 'wash-in' period of equilibration called the 'dynamic distribution indices'. These are based on the times required to reach $90 \%$ of full equilibrium after standardizing for the alveolar ventilation during this period, as described by Bentivoglio, Beerel, Bryan, Stewart, Rose, and Bates (1963b).

\section{RESULTS}

The detailed results are shown in Tables $\mathrm{I}$ to $\mathrm{V}$. Table I shows the grading of the symptoms in

\section{T A B L E I}

GRADING $^{1}$ OF SYMPTOMS IN SEVEN PATIENTS WITH MACLEOD'S SYNDROME

\begin{tabular}{|c|c|c|c|c|c|}
\hline $\begin{array}{c}\text { Subject } \\
\text { (Age/ } \\
: \text { Sex) }\end{array}$ & Cough & Sputum & $\begin{array}{l}\text { History } \\
\text { of } \\
\text { Recent } \\
\text { Chest } \\
\text { Illness }\end{array}$ & $\begin{array}{l}\text { Breath- } \\
\text { lessness }\end{array}$ & $\begin{array}{l}\text { History of } \\
\text { Childhood } \\
\text { Illness }\end{array}$ \\
\hline \multirow{4}{*}{$\begin{array}{c}\text { M.E. } \\
\text { (18 F) } \\
\text { A.K. } \\
(46 \text { M) } \\
\text { A.S. } \\
(53 \text { M) } \\
\text { E.L. M } \\
(47 \text { M) }\end{array}$} & 2 & 0 & 1 & 0 & \multirow{7}{*}{$\begin{array}{l}\text { 'Born with } \\
\text { bronchitis' } \\
\text { Serious chest } \\
\text { illness aged } 9 \\
\text { months } \\
\text { Cough since age } \\
2 \text { years } \\
\text { Double pneumonia } \\
\text { and bronchitis } \\
\text { as a baby } \\
\text { Double pneumonia } \\
\text { aged } 8 \text { years } \\
\text { Pneumonia } \\
\text { aged } 2 \text { years } \\
\text { Pneumonia and } \\
\text { pleurisy }\end{array}$} \\
\hline & 0 & 0 & 2 & 3 & \\
\hline & 2 & 2 & 2 & 3 & \\
\hline & 2 & 2 & 2 & 4 & \\
\hline \multirow{3}{*}{$\begin{array}{l}\underset{\text { (41.C }}{\text { M }}) \\
\text { M.D. } \\
(28 \text { M) } \\
\text { H.S. } \\
(54 \text { F })\end{array}$} & 2 & 2 & 2 & 3 & \\
\hline & 1 & 1 & 2 & 2 & \\
\hline & 1 & 1 & 0 & 5 & \\
\hline
\end{tabular}

1 Graded according to severity as set out in the Instructions (Revised 1962) for the Use of the Questionnaire on Respiratory Symptoms (1960) approved by the Medical Research Council

each patient. For the purposes of this study we decided that a patient suffered from chronic bronchitis when he had at least grade 1 cough and sputum coupled with grade 2 for history of chest illness. Judged by these criteria four of the patients were bronchitic. It is worth noticing that six of the patients had limitation of exercise tolerance due to shortness of breath, which varied between the patients from mild to quite severe.

Table II shows the lung volume, ventilatory capacity, and airway conductance data. In five of the patients the functional residual capacity is raised beyond the predicted values by an average of $1,085 \mathrm{ml}$. and the ratio of residual volume to total lung capacity is higher than normal in all cases. Vital capacity is reduced in every instance and six of the patients have gross air-trapping as shown by the difference between the vital capacity and the F.V.C. In five of the patients the F.E.V.1.0 $:$ F.V.C. ratio is at or below $40 \%$. Airway conductance is abnormal in five out of seven, is normal in one, and higher than the predicted value in the last.

The gas transfer factors at rest and during exercise are shown in Table III. At rest, all the values are low except one (M. E.) and fail to rise satisfactorily on exercise in all except one (D. C.). Percentage extraction is below normal in four.

Table IV shows the findings of arterial blood gas analysis. The $p \mathrm{H}$ and the percentage saturation of oxyhaemoglobin in arterial blood is normal in all cases, but the $\mathrm{Po}_{2}$ was below $95 \mathrm{~mm}$. $\mathrm{Hg}$ at rest in five patients. After exercise only one of these five patients had a $\mathrm{Po}_{2}$ above 95 mm. Hg. In two (A. K. and A.S.) the $\mathrm{Po}_{2}$ fell with exercise further below the normal value. The $\mathrm{PCO}_{2}$ at rest was below the normal range (36 to $42 \mathrm{~mm} . \mathrm{Hg}$ ) in two patients, indicating hyperventilation. In neither case did it rise to within normal limits with exercise. In one further patient (A. K.) the $\mathrm{PCO}_{2}$ rose with exercise to $46 \mathrm{~mm}$. $\mathrm{Hg}$.

The regional ventilation and perfusion findings are shown in Table $V$. The $V$-indices and Q-indices are reduced only in the transradiant lungs. In all the patients the $\mathrm{V}$-indices are reduced in the lower zones; in addition the mid-zone is involved in two patients. The Q-indices are reduced wherever the V-indices are reduced; the perfusion of the mid-zone of the transradiant side in two of the patients (D.C. and A.S.) is reduced without evidence of reduction of ventilation. The dynamic distribution indices are impaired on the transradiant side in all zones in all the patients $D$ except H. S., and in addition this value is low in five of the patients in at least one region on the $N$ opposite side ; in two of the patients (E. L. and H. S.) the whole of this lung is affected.

\section{DISCUSSION}

Our patients were culled from a 'hospital $\stackrel{\mathbb{\complement}}{\stackrel{\odot}{+}}$ population', and to this extent cannot, perhaps, 0 be taken as typical representatives of all subjects $\overline{0}$ who might exhibit Macleod's syndrome. This $\mathbb{D}$ point is relevant in considering the frequency of $\vec{D}$ symptoms in these cases. Bates and Christie (1964) write that 'there may be no dyspnoea even 
T A B LE II

SUBDIVISIONS OF LUNG VOLUME, FLOW RATES, AND AIRWAY CONDUCTANCE MEASUREMENTS IN SEVEN PATIENTS WITH MACLEOD'S SYNDROME ${ }^{1}$

\begin{tabular}{|c|c|c|c|c|c|c|}
\hline \multirow{2}{*}{$\begin{array}{c}\text { Name } \\
(\text { Age } / \text { Sex })\end{array}$} & \multirow{2}{*}{$\begin{array}{c}\text { F.R.C. (ml.) } \\
\text { (Predicted F.R.C.) }\end{array}$} & \multirow{2}{*}{$\frac{\text { R.V. }}{\text { T.L.C. }}$} & \multirow{2}{*}{$\begin{array}{c}\text { V.C. (ml.) } \\
\text { (Predicted V.C.) }\end{array}$} & \multirow{2}{*}{$\frac{\text { F.E.V.1.0 }}{\text { F.V.C. }}$} & \multicolumn{2}{|c|}{$\begin{array}{c}\text { Airway Conductance (C) and } \\
\text { Lung Volume (V) at which } \\
\text { it was measured }\end{array}$} \\
\hline & & & & & C (1./sec. $)$ & V (1.) \\
\hline $\begin{array}{l}\text { M.E. } \\
(18 \quad \text { F })\end{array}$ & $\begin{array}{c}2,400 \\
(2,670)\end{array}$ & $\frac{1,930}{4,600}=44 \%$ & $\begin{array}{c}2,600 \\
(3,600)\end{array}$ & $\frac{1,800}{2,600}=69 \%$ & $0 \cdot 250$ & $2 \cdot 01$ \\
\hline $\begin{array}{c}\text { A.K. } \\
(46 \quad \mathrm{M})\end{array}$ & $\begin{array}{c}4,430 \\
(3,480)\end{array}$ & $\frac{4,180}{7,280}=58 \%$ & $\begin{array}{c}3,100 \\
(4,050)\end{array}$ & $\frac{1,000}{2,600}=38 \%$ & $0 \cdot 121$ & $7 \cdot 65$ \\
\hline (53 $\mathrm{M})$ & $\begin{array}{c}5,400 \\
(3,740)\end{array}$ & $\frac{3,700}{7,200}=52 \%$ & $\begin{array}{c}3,500 \\
(4,360)\end{array}$ & $\frac{900}{2,900}=31 \%$ & $0 \cdot 267$ & 5.92 \\
\hline $\begin{array}{l}\text { E.L. } \\
\left(47^{\mathrm{M}}\right)\end{array}$ & $\begin{array}{c}4,700 \\
(2,980)\end{array}$ & $\frac{4,030}{6.400}=63 \%$ & $\begin{array}{c}2,400 \\
(3,400)\end{array}$ & $\frac{650}{2,050}=32 \%$ & 0.23 & $6 \cdot 32$ \\
\hline $\begin{array}{l}\text { D.C. } \\
(41 \quad M)\end{array}$ & $\begin{array}{c}5,300 \\
(4,250)\end{array}$ & $\frac{4,500}{8,050}=56 \%$ & $\begin{array}{c}3,500 \\
(5,300)\end{array}$ & $\frac{1,000}{2,500}=40 \%$ & $0 \cdot 183$ & $8 \cdot 10$ \\
\hline $\begin{array}{l}\text { M.D. } \\
(28 \quad M)\end{array}$ & $\begin{array}{c}4,750 \\
(3,990)\end{array}$ & $\frac{3,730}{6,550}=58 \%$ & $\begin{array}{c}2,800 \\
(5,280)\end{array}$ & $\frac{900}{2,450}=37 \%$ & 0.105 & $5 \cdot 30$ \\
\hline $\begin{array}{c}\text { H.S. } \\
(54 \quad \text { F })\end{array}$ & $\begin{array}{r}2,330 \\
(2,900) \\
\end{array}$ & $\frac{2,080}{4,0 \varepsilon 0}=50 \%$ & $\begin{array}{c}2,050 \\
(3,220) \\
\end{array}$ & $\frac{1,200}{1,800}=67 \%$ & 0.247 & $2 \cdot 42$ \\
\hline
\end{tabular}

${ }_{1}$ The predicted values are derived from Bates and Christie (1964).

T A B L E I I I

GAS TRANSFER FACTORS (TLCO) FOR CARBON MONOXIDE AT REST AND DURING EXERCISE AND PERCENTAGE EXTRACTION OF $\mathrm{CO}_{2}$ AT REST

\begin{tabular}{|c|c|c|c|c|c|}
\hline $\begin{array}{c}\text { Patient } \\
\text { (Age/ } \\
\text { Sex) }\end{array}$ & $\begin{array}{c}\text { TLco at } \\
\text { Rest }\end{array}$ & $\begin{array}{c}\text { Total } \\
\text { Venti- } \\
\text { lation } \\
\text { (1./min.) }\end{array}$ & $\begin{array}{c}\text { Percen- } \\
\text { tage } \\
\text { Extraction }\end{array}$ & $\begin{array}{c}\text { TLco } \\
\text { during } \\
\text { Exercise }\end{array}$ & $\begin{array}{c}\text { Venti- } \\
\text { lation } \\
\text { (1./min.) }\end{array}$ \\
\hline $\begin{array}{c}\text { M.E. } \\
(18 \text { F) } \\
\text { A.K. } \\
(46 \text { M) } \\
\text { A.S. } \\
(53 . M) \\
\text { E.L. } \\
(47 . \dot{M}) \\
\text { D.C. } \\
(41 \text { M }) \\
\text { M.D. } \\
(28 \text { M }) \\
\text { H.S. } \\
(54 \text { F) }\end{array}$ & $\begin{array}{c}17.7 \\
(21.9) \\
9.4 \\
(15.5) \\
8.9 \\
(16.9) \\
10.4 \\
(19.3) \\
9.1 \\
(20.0) \\
20.9 \\
(23.2) \\
9.8 \\
(14.6)\end{array}$ & $\begin{array}{r}11 \cdot 0 \\
13 \cdot 0 \\
8 \cdot 7 \\
7 \cdot 0 \\
10 \cdot 1 \\
10 \cdot 4 \\
11 \cdot 3\end{array}$ & $\begin{array}{c}49 \\
(55) \\
30 \\
(40) \\
37 \\
(40) \\
44 \\
(46) \\
39 \\
(46) \\
48 \\
(53) \\
33 \\
(44)\end{array}$ & $\begin{array}{c}17.9 \\
(25.0) \\
15.2 \\
(28.0) \\
12.0 \\
(29.0) \\
13.2 \\
(30.0) \\
27.8 \\
(35.0) \\
22.4 \\
(45.0) \\
13.4 \\
(28.0)\end{array}$ & $\begin{array}{l}15 \\
21 \cdot 6 \\
19 \cdot 0 \\
15 \cdot 4 \\
27 \cdot 6 \\
20 \cdot 9 \\
23.8\end{array}$ \\
\hline
\end{tabular}

The predicted values (taken from Bates and Christie, 1964) appear beneath the observed values in parentheses.

on moderate exertion', but we find that five out of seven of our patients become short of breath on walking at an ordinary pace on level ground (breathlessness grade 3-Table I). We find that young patients, such as M.E. in our series, seldom complain of any symptoms, but when questioned they may admit to somé abnormal limitation of exercise tolerance. Only four of our patients were investigated specifically on account of breathlessness, the others being referred because of the abnormal radiological pattern. We cannot dispute the widely held opinion that patients who have this condition show symptoms only when the contralateral lung is affected by other disease, such as bronchitis, but we wonder whether it is likely that the sound lung can escape completely from the childhood infection which some authorities (Reid and Simon, 1962) think is the initial cause of the condition. It is interesting to note in this connexion that unequivocal evidence of a serious childhood chest infection is available in all except one of our patients (Table I). We judged four of them to be bronchitic, and six had histories of recent chest infection. These findings regarding the proportion with chronic

\section{T A B L E IV}

ARTERIAL BLOOD-GAS MEASUREMENTS BEFORE AND IMMEDIATELY AFTER EXERCISE IN SEVEN PATIENTS SHOWING MACLEOD'S SYNDROME

\begin{tabular}{|c|c|c|c|c|c|c|c|c|}
\hline \multirow{2}{*}{$\begin{array}{l}\text { Name } \\
\text { (Age/ } \\
\text { Sex) }\end{array}$} & \multicolumn{4}{|c|}{ At Rest } & \multicolumn{4}{|c|}{ After Exercise } \\
\hline & $\begin{array}{c}\mathrm{O}_{2} \\
\text { Sattn. } \\
(\%)\end{array}$ & $\underset{\mathbf{H g})}{\mathrm{PO}_{2}}$ & $\begin{array}{c}\mathrm{PCO}_{2} \\
\underset{\mathbf{H g}}{\mathbf{H g}} .\end{array}$ & $p \mathrm{H}$ & $\underset{(\%)}{\mathrm{O}_{2}}$ & $\begin{array}{c}\mathrm{Po}_{2} \\
\text { (mm. } \\
\mathbf{H g})\end{array}$ & $\begin{array}{c}\mathrm{PCO}_{2} \\
\mathrm{Hm} \text {. }\end{array}$ & $p \mathbf{H}$ \\
\hline M.E. & $98 \cdot 5$ & 108 & $32 \cdot 0$ & $7 \cdot 43$ & $99 \cdot 0$ & 112 & $31 \cdot 5$ & $7 \cdot 43$ \\
\hline A.K. & $96 \cdot 0$ & 88 & $41 \cdot 0$ & $7 \cdot 40$ & $95 \cdot 0$ & 84 & $46 \cdot 0$ & $7 \cdot 34$ \\
\hline A.S & $97 \cdot 0$ & 94 & $41 \cdot 0$ & $7 \cdot 39$ & $95 \cdot 0$ & 85 & $39 \cdot 0$ & $7 \cdot 38$ \\
\hline E.L. & $95 \cdot 0$ & 80 & $39 \cdot 0$ & $7 \cdot 40$ & - & 一 & - & - \\
\hline D.C. & $97 \cdot 0$ & 96 & $39 \cdot 0^{-}$ & $7 \cdot 40$ & $97 \cdot 0$ & 98 & $42 \cdot 0$ & $7 \cdot 40$ \\
\hline M.D. & $96 \cdot 0$ & 86 & $38 \cdot 0$ & $7 \cdot 39$ & $97 \cdot 0$ & 97 & $39 \cdot 0$ & $7 \cdot 34$ \\
\hline$\underset{(54}{\text { H.S. }}$ F) & 96.0 & 90 & 35.0 & $7 \cdot 42$ & $96 \cdot 0$ & 93 & $32 \cdot 0$ & $7 \cdot 43$ \\
\hline
\end{tabular}




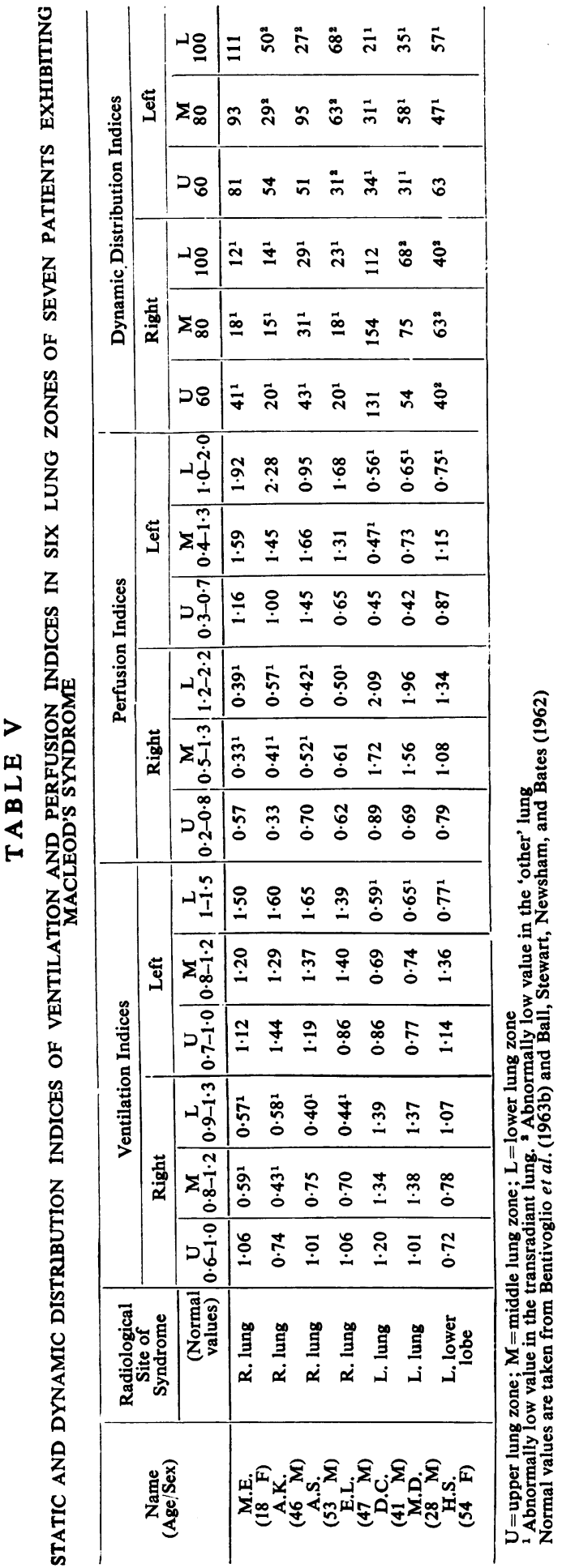

bronchitis and respiratory illness cannot be extrapolated to all subjects with Macleod's syndrome, since an unknown number may have trivial or no symptoms and remain undetected.

We agree with all previous writers on this topic that the adequate functioning of the better lung is of prime importance to the patient. For this reason we have made a number of deductions from our laboratory data. Consider first the vital capacity. Bronchospirometric observations on normal subjects have shown that this should be distributed between the two lungs in the proportion of $54 \%$ on the right side and $46 \%$ on the left (Svanberg, 1957). In Table.VI we have partitioned the predicted vital capacity of all our patients in this way. These results can be compared with the estimates of the distribution of the observed vital capacity which we have made from the regional lung function data.

\section{T A B L E V I}

CALCULATED DISTRIBUTION OF OBSERVED VITAL CAPACITY OF SEYEN PATIENTS EXHIBITING MACLEOD'S SYNDROME. THE NORMAL PARTITION OF THE PREDICTED VITAL CAPACITIES ARE SHOWN FOR COMPARI-

\begin{tabular}{|c|c|c|c|c|c|}
\hline \multirow{3}{*}{$\begin{array}{c}\text { Patient } \\
\text { (Age/ } \\
\text { Sex) }\end{array}$} & \multirow{3}{*}{$\begin{array}{c}\text { Side } \\
\text { Affected }\end{array}$} & \multicolumn{4}{|c|}{ Vital Capacity (1.) } \\
\hline & & \multicolumn{2}{|c|}{ Worse Lung } & \multicolumn{2}{|c|}{ Better Lung } \\
\hline & & Calculated & Predicted ${ }^{1}$ & Calculated & Predicted $^{1}$ \\
\hline & Right & 0.94 & 1.94 & 1.66 & 1.66 \\
\hline & Right & 0.84 & $2 \cdot 19$ & $2 \cdot 23$ & 1.86 \\
\hline & Right & $1 \cdot 23$ & $2 \cdot 35$ & $2 \cdot 27$ & 2.01 \\
\hline & Right & 0.62 & 1.89 & $1 \cdot 78$ & 1.61 \\
\hline & Left & $2 \cdot 21$ & $2 \cdot 44$ & $1 \cdot 29$ & $2 \cdot 86$ \\
\hline M.D. & Left & $1 \cdot 10$ & $2 \cdot 26$ & $1 \cdot 70$ & 3.02 \\
\hline$\underset{\left(54 . S_{\dot{F}}\right.}{\text { H. }}$ & Left & $1 \cdot 23$ & 1.53 & 0.82 & 1.79 \\
\hline
\end{tabular}

1 Predicted vital capacity taken from tables published in Respira. tory Function in Disease, Bates, D. V., and Christie, R. V., Philadelphia, 1964

The manner in which the calculation was made can be most easily explained by taking the first patient (M. E.) as an example. When this patient took a vital capacity breath of gas from the spirometer containing a trace of radioactive xenon, the counters over the chest wall gave readings which were a measure of all the radioactive gas which entered the part of the lung 'seen' by the counters. The sum of all the readings on one side may be taken as an estimate of the total amount inhaled on that side. In this case the total counts on the right amounted to 304 per 
second and on the left to 552. The total observed vital capacity was $2.60 \mathrm{l}$. Dividing this in the proportion of the observed counting rates we find that $0.94 \mathrm{l}$. entered the right lung and 1.661 . the left. The predicted figures for the two lungs are 1.941 . on the right and 1.661 . on the left. We conclude that the low vital capacity of the right lung (the affected one) is responsible for the loss in the total vital capacity which we observed on the spirogram, since the vital capacity on the other side is normal. The situation is not really as simple as this, however, because in cases of this sort, where one lung fails to expand normally, the other lung may be distended by an unusually low intrathoracic pressure at maximum inspiration. When measuring the vital capacity, the extent of such overdistension depends, of course, upon the compliance of the expanding lung. Similar calculations for the other cases show that in four of the seven the vital capacity of the unaffected lung was normal, but it was raised beyond the predicted value in three (A. K., A.S., and E. L.).

In a somewhat similar way it is possible to assess the conductance of the airways of the lungs separately. We bear two facts in mind; first, that in a conducting system arranged in parallel, as the lungs are, the total conductance is equivalent to the sum of the conductances of its parallel components; secondly, that as Briscoe and DuBois have shown (1958), the conductance of the normal lung is directly proportional to its volume. We predicted the conductance of the better lung from its estimated volume. The lung volume at which conductance was measured was divided between the two lungs in the ratio of the sums of the counting rates on each side after the equilibration part of the regional function test; these rates are proportional to the volumes of lung surveyed in the various regions. The predicted conductance for the better lung was then calculated from the formula Conductance $=0.13 \times$ lung volume (Briscoe and DuBois, 1958). In five out of the seven patients the values thus predicted for the better lung (see Table VII) are between two and three times the observed value for both lungs together. This means that, even if the conductance of the affected lung were negligible, that of the better lung is still below the normal range. It is quite possible that the observed values for total conductance are, in fact, due mostly to the contributions of this lung because the rapid, shallow breathing which is used during the measurement of airway conductance will reduce the ventilation of the abnormal lung
T A B L E V I I

OBSERVED LUNG VOLUMES AND CONDUCTANCES MEASURED AT THE SAME TIME IN SEVEN PATIENTS EXHIBITING MACLEOD'S SYNDROME

\begin{tabular}{|c|c|c|c|c|c|c|}
\hline $\begin{array}{l}\text { Patient } \\
\text { (Age/ } \\
\text { Sex) }\end{array}$ & $\begin{array}{c}\text { Side } \\
\text { Affected }\end{array}$ & $\begin{array}{c}\text { Lung } \\
\text { Volume } \\
(1 .)\end{array}$ & $\begin{array}{l}\text { Observed } \\
\text { Total } \\
\text { Conduc- } \\
\text { tance } \\
\text { (l.'sec.l } \\
\text { cm. } \mathrm{H}_{2} \mathrm{O} \text { ) }\end{array}$ & $\begin{array}{c}\text { Predicted } \\
\text { Total } \\
\text { Conduc- } \\
\text { tance } \\
\left(1 . / \text { sec. }^{\prime} /\right. \\
\left.\mathrm{cm} . \mathrm{H}_{\mathbf{2}} \mathrm{O}\right)\end{array}$ & 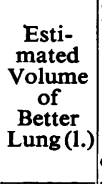 & $\begin{array}{c}\text { Expected } \\
\text { Conduc- } \\
\text { tance } \\
\text { of } \\
\text { Befter } \\
\text { Lung } \\
\text { (1.'sec.! } \\
\text { cm. } \mathrm{H}_{2} \mathrm{O} \text { ) }\end{array}$ \\
\hline & Right & $2 \cdot 01$ & 0.260 & 0.263 & 1.00 & $0 \cdot 130$ \\
\hline & Right & $7 \cdot 70$ & 0.121 & 1.001 & $4 \cdot 16$ & 0.540 \\
\hline & Right & 5.92 & 0.267 & 0.770 & $3 \cdot 15$ & 0.410 \\
\hline & Right & 6.00 & 0.285 & 0.780 & 3.46 & 0.450 \\
\hline & Left & $8 \cdot 1$ & 0.192 & 1.050 & $4 \cdot 73$ & 0.615 \\
\hline & Left & $5 \cdot 3$ & 0.105 & 0.690 & $2 \cdot 70$ & 0.350 \\
\hline H.S.S. & Left & $2 \cdot 42$ & 0.247 & 0.314 & 1.26 & 0.150 \\
\hline
\end{tabular}

The lowest expected conductance of the contralateral lung is calculated from its estimated volume on the assumption that the airways are normal. The predicted conductance is similarly calculated from the lung volume given in column 3 .

to a minimum. We conclude, therefore, that the conductance of the so-called normal lung is low in most of our patients. In the two exceptions to this, one (M. E.) had no spirographic evidence of airways obstruction and the other (H. S.) had only the lower lobe of the left lung affected and also had little gross evidence of airways obstruction overall. One consequence of this uneven distribution of airway conductance can be seen in the distribution and mixing of inspired gas within the lung. As shown in Table IV, mixing is slow in the transradiant lung in every patient and is also uneven on the unaffected side in all except two patients.

It is no surprise to find that the gas transfer factors are abnormal in patients who have such a serious derangement of at least a large part of one lung, nor is there any difficulty in reconciling these findings with the measurements of the arterial blood gas pressures. The most probable explanation for both abnormalities is in the relative unevenness of ventilation and blood flow in the lungs. Calculations of the blood-gas tensions which we would expect to find in our patients have been made from the cbserved ventilation/ perfusion ratios tabulated in Table VIII. These estimates matched unexpectedly well with the measurements on arterial blood-within $2 \mathrm{~mm}$. $\mathrm{Hg}$ for $\mathrm{Po}_{2}$ and $5 \mathrm{~mm}$. $\mathrm{Hg}$ for $\mathrm{PcO}_{2}$; these errors are well within the error of estimation of the blood gases themselves. Two conclusions are justifiable ; one, that there is no need to invoke 
T A B LE VIII

VALUES OF VENTILATION:PERFUSION RATIO DERIVED FROM REGIONAL LUNG-FUNCTION STUDIES IN SEVEN PATIENTS EXHIBITING MACLEOD'S SYNDROME

\begin{tabular}{|c|c|c|c|c|c|c|c|}
\hline \multirow{2}{*}{ Name } & \multirow{2}{*}{$\begin{array}{c}\text { Side } \\
\text { Affected }\end{array}$} & \multicolumn{3}{|c|}{ Right } & \multicolumn{3}{|c|}{ Left } \\
\hline & & $\mathrm{U}$ & $\mathbf{M}$ & L & $\mathrm{U}$ & $\mathbf{M}$ & L \\
\hline $\begin{array}{l}\text { M.E. } \\
\text { A.K. } \\
\text { A.S. } \\
\text { E.L. } \\
\text { D.C. } \\
\text { M.D. } \\
\text { H.S. }\end{array}$ & $\begin{array}{l}\text { Right } \\
\text { Right } \\
\text { Right } \\
\text { Right } \\
\text { Left } \\
\text { Left } \\
\text { Left }\end{array}$ & $\begin{array}{l}1.86 \\
2.22 \\
1.44 \\
1.71 \\
1.35 \\
1.46 \\
0.91\end{array}$ & $\begin{array}{l}1.79 \\
1.05 \\
1.44 \\
1.15 \\
0.78 \\
1.13 \\
0.72\end{array}$ & $\begin{array}{l}0.88 \\
0.66 \\
0.70 \\
0.81\end{array}$ & $\begin{array}{l}0.97 \\
1.44 \\
0.82 \\
1.32 \\
1.91 \\
1.83 \\
1.31\end{array}$ & $\begin{array}{l}0.76 \\
0.89 \\
0.83 \\
1.07 \\
1.47 \\
1.01 \\
1 \cdot 18\end{array}$ & $\begin{array}{l}0.78 \\
0.70 \\
1.79 \\
0.83 \\
1.05 \\
1.00 \\
1.03\end{array}$ \\
\hline \multicolumn{2}{|c|}{$\begin{array}{l}\text { Normal } \\
\text { Ball et al., } \\
\quad 1962 \\
\text { Mannell et al., } \\
1966\end{array}$} & $\begin{array}{l}1.75 \\
1.64\end{array}$ & $\begin{array}{l}1.73 \\
1.07\end{array}$ & $\begin{array}{l}0.65 \\
0.76\end{array}$ & $\begin{array}{l}1.58 \\
1.72\end{array}$ & $\begin{array}{l}1.58 \\
1.19\end{array}$ & $\begin{array}{l}0.81 \\
0.90\end{array}$ \\
\hline
\end{tabular}

$\mathrm{U}=$ upper lung zone; $\mathrm{M}$-middle lung zone; $\mathrm{L}=$-lower lung zone.

any interference with gas transfer across the alveolar wall to explain the low gas transfer factors, and the other, that the values we obtain for regional ventilation: perfusion ratios and for regional blood-flow are quite reliable in cases of this kind. The same need not be true as far as the ratio is concerned in other conditions where blood and gas may not confront one another at all in some parts of the lung.

The failure of the gas transfer factors to increase significantly during exercise in some patients is an important finding. The mechanism of the increase in normal subjects is partly a redistribution of blood in the lung which allows better perfusion of poorly perfused parts of the lungs such as the apical regions and possibly also by the opening of alveoli which may be functionless at rest. Calculations based on our regional data indicate that, on the average, the better lung receives about $75 \%$ of the available blood-flow and $67 \%$ of the ventilation. This lends some support to our hypothesis that this lung is already working to capacity at rest, leaving little scope for increased efficiency during exercise.

The correlation of clinical signs and radiographic appearances with laboratory measurements is of practical importance. In the present study we have attempted to assess air entry stethoscopically in the six regions of the lungs subsequently surveyed by the scintillation counters. Broadly speaking, the clinical assessments agree with the ventilation indices, but the discrimination obtainable with the stethoscope is, as would be expected, dependent upon rather coarse contrasts. In general, breath sounds were not found to be diminished unless the ventilation index was less than $0 \cdot 5$, but differences in the ventilation index as small as $\mathbf{0 \cdot 2}$ may occasionally be detected clinically in adjacent zones of one lung. Similarly, we have tried to predict the distribution of blood-flow from the apparent calibre and distribution of the pulmonary vascular shadows in the radiographs. Although we found some agreement between radiographic and radio-isotope estimates, we were unable to assess this in a qualitative way as we could for ventilation and stethoscopic findings. We have come to regard the radioactive xenon studies as an extension of careful clinical and radiological assessment to which it adds precision and in some cases reveals unsuspected disturbances of perfusion and ventilation, and particularly regional variations in gas mixing.

Inevitably we have received help from many colleagues in carrying out this work. In particular we should like to thank Professor J. G. Scadding, whose informed interest in our activities is always stimulating and helpful. Also we should like to acknowledge the essential help which we received from Mr. M. D. Foskett, our chief technician, in maintaining the complicated equipment we have used and in assisting with the regional function tests. Dr. J. Gough gave us an expert opinion on the radiological data which we collected and aroused our interest in the correlations between his work and our own. Our colleagues on the staff of the Brompton Hospital very kindly referred their patients to us for investigation, and the patients themselves, our real source of information, have earned our special thanks for their co-operation in undergoing the rigours of the investigations repcrted here.

\section{REFERENCES}

Ball, W. C., Jr., Stewart, P. B., Newsham, L. G. S., and Bates, D. V. (1962). Regional pulmonary function studied with xenon ${ }^{133}$ J. clin. Invest., 41, 519 .

Bates, D. V., Boucot, N. G., and Dormer, A. E. (1955). The pulmonary diffusing capacity in normal subjects. J. Physiol. (Lond.) 129, 237.

and Christie, R. V. (1964). Respiratory Function in Disease: An Introduction to the Integrated Study of the Lung, p. 207. W. B. Saunders, Philadelphia and London.

Belcher, J. R., Capel, L., Pattinson, J. N., and Smart, J. (1959) Hypoplasia of the pulmonary arteries. Brit. J. Dis. Chest, 53,

Bentivoglio, L. G., Beerel, F., Stewart, P. B., Bryan, A. C., Ball, W. C., Jr., and Bates, D. V.. (1963a). Studies of region C., Ball, tion and perfusion in pulmonary emphysema using xenon ${ }^{133}$ Amer. Rev. resp. Dis., 88, 315.

Bryan, A. C., Stewart, P. B., Rose, B., and Bates, D. V (1963b). Regional pulmonary function studied with xenon ${ }^{13}$ in patients with bronchial asthma. J. clin. Invest., 42, 1193.

Briscoe, W. A., and DuBois, A. B. (1958). The relationship between airway resistance, airway conductance and lung volume in subjects of different age and body size. Ibid.. 37, 1279.

Comroe, J. H., Jr., Botelho, S. Y., and DuBois, A. B. (1959). Design of a body plethysmograph for studying cardiopulmonary physiology. J. appl. Physiol., 14, 439.

Darke, C. S., Chrispin, A. R., and Snowden, B. S. (1960). Unilateral lung transradiancy: a physiological study. Thorax, 15, 74 . 
Dill, D. B. (1944). Handbook of Respiratory Data in Aviation. National Research Council, Washington.

Dornhorst, A. C.. Heaf, P. J., and Semple, S. J. G. (1957). Unilateral 'emphysema'. Lancet, 2, 873.

Fletcher, C. M., Hugh-Jones, P., McNicol, M. W., and Pride, N. B. (1963). The diagnosis of pulmonary emphysema in the presence of chronic bronchitis (Appendix). Quart. J. Med., 32 , 33.

Fouché, R. F., Spears, J. R., and Ogilvie, C. (1960). Unilateral emphysema. Brit. med. J., 1, 1312 .

Macleod, W. M. (1954). Abnormal transradiancy of one lung. Thorax, $9,147$.

McMichael, J. (1939). A rapid method of determining iung capacity. Clin. Sci., 4, 167.
Mannell, T., Prime, F. J., and Smith, D. (1966). A practical method for using radioactive xenon in the assessment of regional lung function. Scand. J. resp. Dis., Suppl. No. 62, p. 41.

Medical Research Council's Committee on the Aetiology of Chronic Bronchitis (1960). Standardized questionaries on respiratory symptoms. Brit. med. J., 2, 1665.

Reid, L., and Simon, G. (1962). Unilateral lung transradiancy. Thorax, 17, 230.

Scadding, J. G. (1965). In Clinicopathological Conference: A case of chronic bronchitis with Macleod's syndrome. Brit. med. J., 1, 710.

Svanberg, L. (1957). Influence of posture on the lung volumes, ventilation and circulation in normals. A spirometric-bronchospirometric investigation. Scand. J. clin. Lab. Invest., 9, Suppl. 